\title{
A novel non-intrusive microcell for sound-speed measurements in liquids. Speed of sound and thermodynamic properties of 2-propanone at pressures up to $160 \mathrm{MPa}$
}

\author{
R. Gomes de Azevedo ${ }^{\text {a }}$, J. Szydlowski ${ }^{\text {a,c }}$, P.F. Pires ${ }^{\text {a }}$, J.M.S.S. Esperança ${ }^{\text {b, }}$ \\ H.J.R. Guedes ${ }^{b}$, L.P.N. Rebelo ${ }^{a, *}$ \\ a Instituto de Tecnologia Química e Biológica, ITQB 2, Universidade Nova de Lisboa, Av.República, Apartado 127, 2780-901 Oeiras, Portugal \\ ${ }^{\mathrm{b}}$ REQUIMTE, Departamento de Química, Faculdade de Ciências e Tecnologia, Universidade Nova de Lisboa, 2829-516 Caparica, Portugal \\ ${ }^{\mathrm{c}}$ Department of Chemistry, Warsaw University, Zwirki i Wigury 101, 02-093 Warsaw, Poland
}

Received 25 June 2003; accepted 2 December 2003

\begin{abstract}
A novel high-pressure, ultrasonic cell of extremely reduced internal dimensions $\left(\sim 0.8 \cdot 10^{-6} \mathrm{~m}^{3}\right)$ and good precision for the determination of the speed of propagation of sound in liquids was conceived and built. It makes use of a non-intrusive methodology where the ultrasonic transducers are not in direct contact with the liquid sample under investigation. The new cell was used to carry out speed of sound measurements in 2-propanone (acetone) in broad ranges of temperature $(265<T / \mathrm{K}<340)$ and pressure $(0.1<p / \mathrm{MPa}<160)$. $(p, \rho, T)$ data for acetone were also determined but in a narrower $T, p$ range $(298$ to $333 \mathrm{~K} ; 0.1$ to $60 \mathrm{MPa})$. In this interval, several thermodynamic properties were thus calculated, such as: isentropic $\left(\kappa_{\mathrm{S}}\right)$ and isothermal $\left(\kappa_{\mathrm{T}}\right)$ compressibility, isobaric thermal expansivity $\left(\alpha_{\mathrm{p}}\right)$, isobaric $\left(c_{\mathrm{p}}\right)$ and isochoric $\left(c_{\mathrm{v}}\right)$ specific heat capacity, and the thermal pressure coefficient $\left(\gamma_{\mathrm{v}}\right)$. Comparisons with values found in the literature generally show good agreement.
\end{abstract}

(c) 2004 Elsevier Ltd. All rights reserved.

Keywords: Speed of sound; Density; Pressure effects; 2-Propanone; Acetone

\section{Introduction}

Measurements of the speed of sound (SS), $u$, in liquids have proven to constitute a powerful source of valuable information about the thermophysical properties of chemical substances and their mixtures [1,2]. Most of the SS data reported in the literature have been obtained via so-called intrusive or invasive methods, where both the transmitter and receiver of the acoustic wave are in direct contact with the media under investigation [3-5], while in a few cases non-intrusive methods have been used [5-9]. The non-intrusive SS cell used in the current work is distinct from other nonintrusive ones in two respects: (a) no long buffer rods

\footnotetext{
${ }^{*}$ Corresponding author. Fax: +351-21-4411-277.

E-mail address: luis.rebelo@itqb.unl.pt (L.P.N. Rebelo).
}

are used (instead, it presents a unique internal shape) and; (b) the internal volume was decreased by one or two orders of magnitude. Commonly, the volume of the liquid to be used is relatively great (typically, of the order of tens or hundreds of $\mathrm{cm}^{3}$ ). The present work reports the development made at the ITQB laboratories in Oeiras of an ultrasonic cell and its apparatus for measuring the speed of sound propagation in liquids, which makes use of a non-intrusive method using an extremely reduced liquid volume $\left(\sim 0.8 \cdot 10^{-6} \mathrm{~m}^{3}\right)$. For this purpose, we designed and built a compact microcell that permits the measurements to be performed by locating the transducers (piezoelectrics) outside the liquid under study. The main advantages of this methodology over traditional invasive and large-volume methods are: (i) the possibility of undertaking measurements on almost any type of liquid, even if it is aggressive or reactive to the piezoelectric materials; (ii) the avoidance 
of possible damage to the piezoelectrics and/or their electric contacts upon pressurization; (iii) the easy generation of high pressures; (iv) the possibility of undertaking studies in metastable regimes, e.g., liquids under tension and/or supercooled; (v) the ability to obtain measurements of SS in very expensive fluids, e.g., isotopically substituted ones. The three latter points are a direct consequence of the extremely reduced volumes involved.

With the dual purpose of testing the novel microcell and associated methodology as well as determining extended high-accuracy data for an important fluid, acetone (2-propanone) was chosen to carry out SS measurements in a broad range of temperature $(265<$ $T / \mathrm{K}<340)$ and pressure $(0.1<p / \mathrm{MPa}<160)$. Due to a surprising lack of extensive high quality data for this compound (considering its importance and popular use) even at low pressure, we have also measured at the REQUIMTE laboratories in Caparica its SS up to $60 \mathrm{MPa}$ using a high-accuracy standard technique [3] which makes use of a double pulse-eco method. To the best of our knowledge there exists only one report [10] on the pressure dependence of the speed of sound in acetone at three isotherms.

This new microcell will be very useful in systematic investigations of the physical properties of various liquids and their mixtures under extreme $(p, T)$ conditions, especially if speed of sound data can be combined with those of density. To this end, a more detailed analysis of the data from the literature revealed that precise density data for acetone [11-14] are only known for very limited temperature and pressure values (mostly at $298 \mathrm{~K}$ and $0.1 \mathrm{MPa}$ ) and there is, thus, a need to perform more systematic measurements of density. Therefore, we have also carried out such measurements in the temperature range (298 to 333) $\mathrm{K}$ and up to $60 \mathrm{MPa}$. Kooner and Van Hook [15] investigated the deuterium isotope effect on several thermodynamic properties of acetone (perprotonated (-h) versus perdeuterated (-d)). The combined results of the speed of sound and density allowed us to calculate other physical properties of acetone such as isoentropic $\left(\kappa_{\mathrm{s}}\right)$ and isothermal $\left(\kappa_{\mathrm{T}}\right)$ compressibilities, isobaric thermal expansivities $\left(\alpha_{\mathrm{p}}\right)$, isobaric $\left(c_{\mathrm{p}}\right)$ and isochoric $\left(c_{\mathrm{V}}\right)$ specific heat capacities and thermal pressure coefficients $\left(\gamma_{\mathrm{v}}\right)$. Whenever available, these values are compared with literature data obtained via other methods.

\section{Experimental}

\subsection{Novel acoustic cell}

In order to measure the speed of propagation of sound waves in liquids using a non-intrusive method, a new cell was designed and built (figure 1). It consists

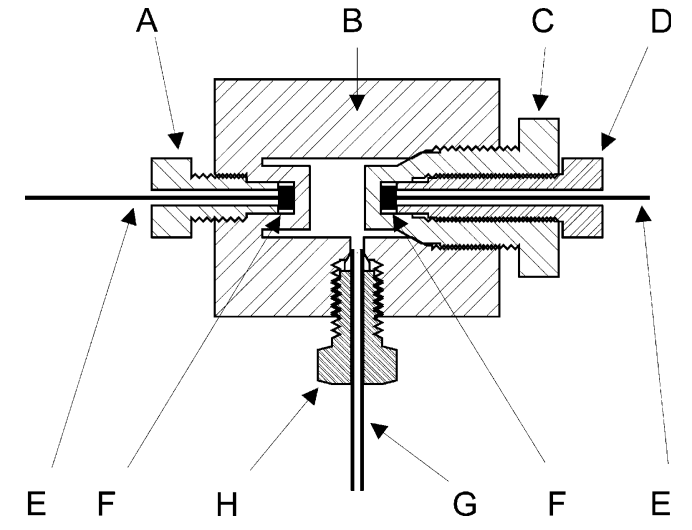

FIGURE 1. Schematic representation of the non-intrusive acoustic microcell with an internal volume of $\sim 0.8 \cdot 10^{-6} \mathrm{~m}^{3}$. A and $\mathrm{D}$, caps holding the PZTs; B, stainless steel cylindrical body; C, cell closure; E, wires for electrical connections; F, piezoelectric transducers; G, 1/16" tubing; $\mathrm{H}$, high-pressure fitting.

roughly of a 316 stainless steel hollow, thick-wall cylinder (diameter and length are approx. $30 \mathrm{~mm}$ and 36 $\mathrm{mm}$, respectively) where two $1 \mathrm{MHz}$ piezoelectric transducers (PZT), one acting as a transmitter and the other as a receiver, are housed in specially designed compartments in the outer section of the cylinder. They are firmly fixed to this outer segment of the stainless steel walls of the cavities, and, additionally, a thin layer of silicone oil has been placed between the PZTs and the stainless steel to achieve better surface contact (thus, enhancing the transmission of the sound wave). After many attempts, the internal geometry was optimised in order to obtain a clean, low-noise acoustical wave signal, highly sensitive to solvent, temperature, and pressure changes. That optimal geometry comprises (in longitudinal section) an "H-shaped" volumetric form. Generally speaking, this type of internal geometry is of vital importance as it forces the sound waves to travel through the liquid while delaying those travelling through the stainless steel body of the cell. The unwanted signals arising from other directions than those containing the liquid reach the receiver later than the main signal. A patent approval (patent filed) has been requested for the current microcell. The total internal volume of the cell (and, the liquid) is very small (less than $\sim 0.8 \cdot 10^{-6} \mathrm{~m}^{3}$ ). The transducers are $3 \mathrm{~mm}$ diameter, $2 \mathrm{~mm}$ thick discs made of a polarised piezoelectric ceramic of lead-titanate-zirconate $\left(\mathrm{PbZrO}_{3} / \mathrm{PbToO}_{3}\right)$. A thin film of silver was deposited on both of their faces, to serve as an electrode. Both PZTs are separated from the liquid sample by a $2 \mathrm{~mm}$ wall of stainless steel. Thus, the main wave leaves the transmitter PZT travelling, first through, ca. $2 \mathrm{~mm}$ of stainless steel, then along a ca. 9 $\mathrm{mm}$ liquid path, and finally, along $2 \mathrm{~mm}$ more of stainless steel, after which it reaches the receptor ultrasonic receptor. Although the fundamental resonance frequency of the ultrasonic transducers is $1 \mathrm{MHz}$, it was 
found that the optimal operational frequency is 0.5 MHz. This can be attributed to the fact that the PZT discs are contained in and fixed to a cavity in the body of the cell, which restricts their vibration modes. Electrical connections to the PZTs were made via multi-wired coaxial cables.

The apparatus, schematically shown in figure 2 , was built using standard high-pressure valves, $1 / 16^{\prime \prime}$ thickwalled tubing, and connectors (HIP). It includes a pressure generator (HIP- model 37-6-30) of $11 \cdot 10^{-6} \mathrm{~m}^{3}$ volume equipped with Teflon sealing o-rings, capable of reaching pressures of the order of $200 \mathrm{MPa}$. Pressure is measured using an Omega pressure transducer, which was calibrated against a high-accuracy Heise gauge. Pressure is measured to both a precision and accuracy better than $\pm 0.05 \%$. In the case of low-cost, low-viscosity, relatively high-vapour pressure fluids (such as acetone) the entire apparatus (pressure generator, pressure sensor, tubing, etc.) is completely filled with the liquid under investigation. Thus, the liquid simultaneously acts as the liquid sample under study and hydraulic fluid as well. Otherwise, the liquid sample only occupies volumes corresponding to the cell and buffer lines. The buffer lines prevent the presence of any traces of hydraulic fluid at any time inside the cell, which would certainly occur upon several pressurization cycles. The acoustic cell is placed in a Hart Scientific calibration bath (stability $\pm 0.001 \mathrm{~K}$ ) and the temperature is measured by a 4-wire platinum resistance thermometer (PRT) coupled with a Keithley digital multimeter (Model DMM 199). The PRT was previously calibrated, thus allowing temperature measurements on the ITS-90 scale with an estimated uncertainty better than $\pm 0.01 \mathrm{~K}$.

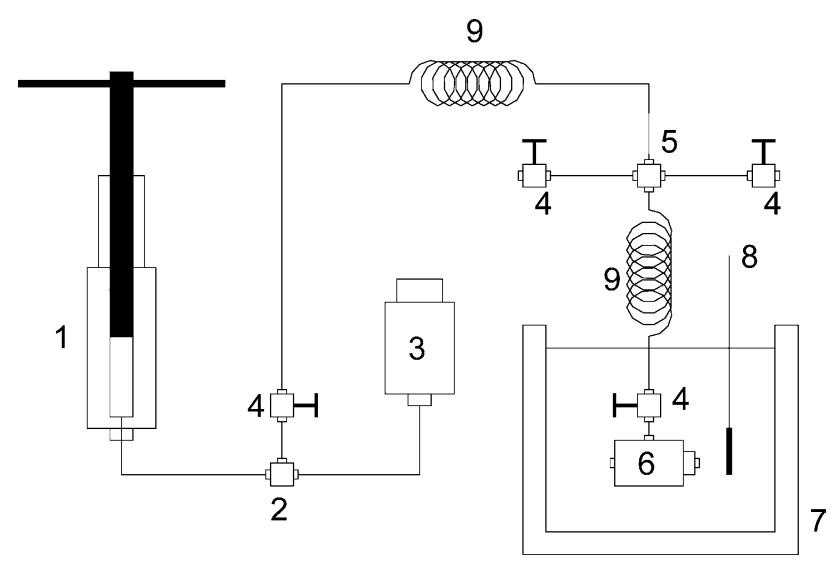

FIGURE 2. Schematic representation of the high-pressure apparatus for the speed of sound measurements: 1, high-pressure generator (screw injector); 2, three-way connector; 3, pressure transducer; 4, high-pressure valves; 5 , four-way connector; 6 , acoustic microcell; 7 , thermostatic bath; 8 , platinum resistance thermometer; $9,1 / 16^{\prime \prime}$ tubing of buffer line.

\subsection{Measurements and chemicals}

To measure the speed of sound, a $0.5 \mathrm{MHz}, 16 \mathrm{~V}$ peakto-peak sinusoidal wave is fed to the transmitter PZT through a Wavetek $50 \mathrm{MHz}$ function generator (Model 80). The signal passes through the metal, the liquid, and the metal again, and it is recognized by the receiver PZT. The response signal is then amplified and sent to a digital oscilloscope (Tektronix, model TDS 3032) where it is analysed. By measuring the total time period between the two instants (the time delay between the initial and final signals, the so-called Time of Flight, $\Delta \tau$ ), one can determine the speed of sound in the liquid. Ideally, this total time is the sum of the periods of time that the wave remains in the two $2 \mathrm{~mm}$ thickness stainless steel walls followed by the $9 \mathrm{~mm}$ long liquid path. Were both these dimensions and the SS in the stainless steel known to very high accuracy (and as a function of $p$ and $T$ ), one could easily determine the SS in the liquid, $u$, by simple difference between these two terms,

$1 / u=K \Delta \tau-K K^{\prime}$,

where $K$ and $K^{\prime}$ are functions weakly dependent on $T$ and $p$ and related, respectively, to the acoustic thickness of the liquid and the acoustic thickness and SS in the metal. In practice, this is not feasible, and a calibration procedure has to be followed. The cell was calibrated by measuring the $\Delta \tau$ of toluene, water, ethanol and tetrachloromethane over broad ranges of pressure $(0.1<p /$ $\mathrm{MPa}<175)$, temperature $(278.15<T / \mathrm{K}<338.15)$ and SS $\left(800<u / \mathrm{m} \cdot \mathrm{s}^{-1}<2000\right)$ using a total of 120 data points, and fitting the data along with the literature values of $u(p, T)$ for these liquids (toluene [16], water [17], ethanol [18], and tetrachloromethane [19]). For this purpose we used the following equation

$$
\begin{aligned}
1 / u= & \left(c_{1}+c_{2} T+c_{3} T^{2}\right)+\left(c_{4}+c_{5} T+c_{6} T^{2}\right) p^{2}+ \\
& \left\{\left(c_{7}+c_{8} T+c_{9} T^{2}\right)+\left(c_{10}+c_{11} T+c_{12} T^{2}\right) p^{2}\right\} \Delta \tau .
\end{aligned}
$$

$K$ and $K^{\prime}$ in equation (1) can thus be empirically determined as a function of $T$ and $p$. On the basis of the statistical evaluation of the residuals between equation (2) and the literature data of the four calibrating fluids, the overall uncertainty (accuracy) of the SS measurements in the full experimental range of pressure, temperature, and speed of sound is estimated to be of the order of \pm 0.1 to 0.2 . This figure mainly reflects some degree of inconsistency between four distinct data sets since the internal precision is slightly better, $\sim \pm 0.05 \%$. This can be judged by the standard deviation of the Pade $3 \times 3$ fit (equation (3), see below) to the data points of acetone obtained with this new microcell. In turn, the uncertainty in the measurement of $\Delta \tau$ is $2 \cdot 10^{-10} \mathrm{~s}$, which contributes to an uncertainty of \pm 0.02 to 0.04 $\mathrm{m} \cdot \mathrm{s}^{-1}$ to $u$, i.e., less than $\pm 0.004 \%$. 
Spectroscopic grade acetone, purchased from Merck, with purity better than $99.9 \%$ (as checked by gas chromatography) was filtered through $0.2 \mu \mathrm{m}$ filters and injected into the cell. In the case of the measurements performed with the novel microcell, the liquid is injected under vacuum to insure the complete filling of the cell. The cell itself had previously been placed in a vacuum oven at $\sim 370 \mathrm{~K}$ for $24 \mathrm{~h}$ to degas the stainless steel and remove traces of water.

This new microcell was tested taking advantage of the parallel measurements we have performed in this work on the speed of sound in acetone using the standard intrusive cell [3] of well-proven reliability. The comparison of the results obtained in the temperature range (288 to 340 ) $\mathrm{K}$ and pressure up to $65 \mathrm{MPa}$ shows that the largest deviations are of the order of $0.2 \%$ (see below), which confirms the usefulness of the new cell.

Densities, $\rho$, in the temperature range (298 to 340 ) K and pressure range (0.1 to 60) $\mathrm{MPa}$ were measured using a previously calibrated Anton Paar DMA 512P vibrating tube densimeter, where temperature is controlled to $\pm 0.01 \mathrm{~K}$ and pressure accuracy and precision are better than $0.05 \%$. The overall density precision is typically $0.002 \%$, while its estimated uncertainty (judging by the residuals of the overall fit in comparison with literature data for the calibrating liquids) is $0.02 \%$.

\section{Results and discussion}

The measured values of the speed of sound and densities of acetone as a function of temperature and pressure are shown in figures 3-5. In the case of the SS, results obtained with this novel cell are compared with those using the standard pulse-eco method (figure 4). Although physical and thermodynamic properties of acetone have been studied for many years, it still appeared that most of the work has been done at room temperature and atmospheric pressure. In particular, using pressure as a variable has been relatively rare. In respect to density, direct measurements over broad ranges of temperature and pressure are practically not available. Actually one needs to extract density from other volumetric measurements and compile data over broader temperature and pressure ranges (French [12], Mahlotra and Woolf [13], Pöhler and Kiran [14]).

Even less data are available for the speed of sound of acetone. Only a few data points are available at atmospheric pressure $[20,21]$ and old data by Eden and Richardson [10] extend the pressure range up to $70 \mathrm{MPa}$ at only three isotherms. The most extensive data on the thermodynamic properties of acetone over broad intervals of temperature (273 to 323 ) $\mathrm{K}$ and pressure (1 to 400) MPa have been given by Malhotra and Woolf [13]. These include calculations of isothermal compressibility $\left(\kappa_{\mathrm{T}}\right)$, isobaric expansivity $\left(\alpha_{\mathrm{p}}\right)$ and isobaric heat capacity

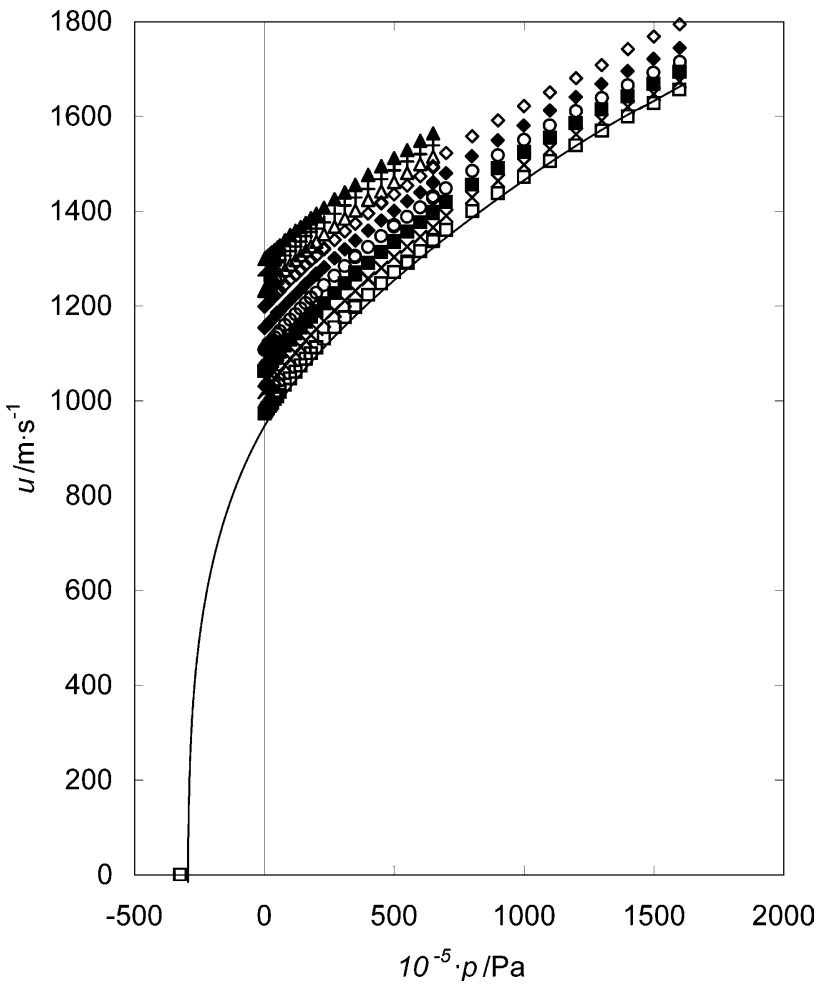

FIGURE 3. Isotherms of the experimental speed of sound, $u$, in acetone. The line (merely a visual guide) shows, qualitatively, how $u$ has to decrease upon depressurisation in order to meet the null value criterion at the mechanical spinodal locus (at the highest experimental temperature). $\square, 338.22 \mathrm{~K} ; \times, 328.33 \mathrm{~K} ; \boldsymbol{\square}, 318.22 \mathrm{~K}$;, $308.22 \mathrm{~K}$; $298.23 \mathrm{~K} ; \diamond, 288.23 \mathrm{~K} ; \triangle, 280.74 \mathrm{~K} ;+, 273.16 \mathrm{~K} ; \boldsymbol{\Lambda}, 265.67 \mathrm{~K}$.

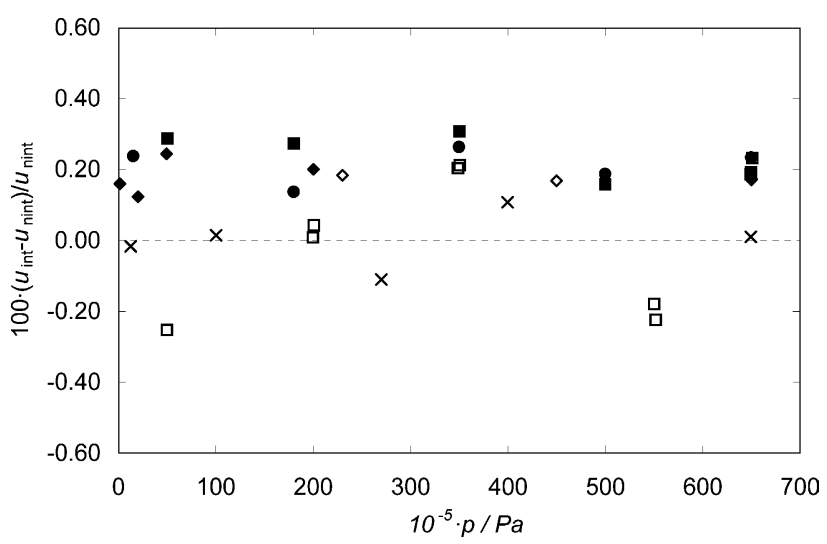

FIGURE 4. Individual experimental data points of $u$ using the nonintrusive (nint) and the standard intrusive (int) methods compared as deviations in percentage. $\square, 338.22 \mathrm{~K} ; \times, 328.33 \mathrm{~K} ; \mathbf{\square}, 318.22 \mathrm{~K}$; , $308.22 \mathrm{~K} ; \diamond, 298.23 \mathrm{~K} ; \diamond, 288.23 \mathrm{~K}$.

$\left(c_{\mathrm{p}}\right)$. The latter has also been determined directly from calorimetric measurements in the temperature range (273 to 325 ) K but only for atmospheric pressure (Low and Moelwyn-Hughes [22], Staveley et al. [23], and French [12]; Ibberson et al. [24] reported $c_{\mathrm{p}}$ from the solid region to the liquid up to $300 \mathrm{~K}$ ). There are no $c_{\mathrm{p}}$ 


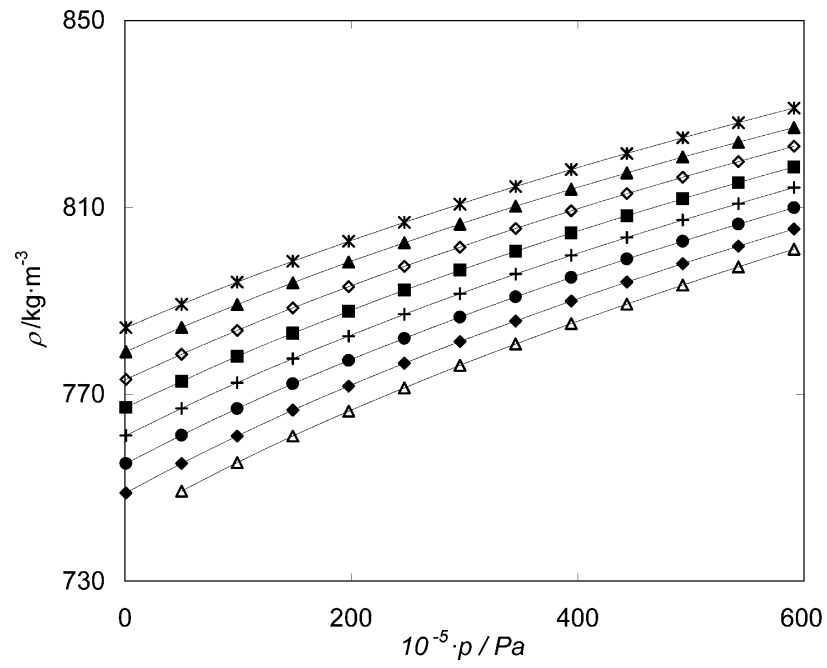

FIGURE 5. Isotherms of the experimental density, $\rho$, of acetone. $\Delta$, $333.04 \mathrm{~K} ; \bullet, 328.06 \mathrm{~K} ; \bullet$ •, $322.93 \mathrm{~K} ;+$, $317.97 \mathrm{~K} ; \boldsymbol{\Delta}, 313.04 \mathrm{~K} ; \diamond$, $308.08 \mathrm{~K} ; \boldsymbol{\Lambda}, 303.10 \mathrm{~K} ; \boldsymbol{*}, 298.15 \mathrm{~K}$.

data determined from direct calorimetric measurements for higher pressures than the atmospheric one.

The speed of sound raw data (more than 360 points) as a function of both temperature and pressure are reported in table 1 . For the sake of economy of size of the table, data are presented for nominal temperatures which, typically, differ from the actual ones by no more than $(0.01$ or 0.02$) \mathrm{K}$. Note that $(\partial u / \partial T)_{p} \sim-(4.25 \pm$ $0.25) \mathrm{m} \cdot \mathrm{s}^{-1} \cdot \mathrm{K}^{-1}$ within the whole $T, p$ range. Original data have been fitted to a Pade $3 \times 3$ equation of the form:

$\left(u / \mathrm{m} \cdot \mathrm{s}^{-1}\right)=\frac{\sum_{i=0}^{2} \sum_{j=0}^{2} a_{i j}(T / \mathrm{K})^{i}(p / \mathrm{MPa})^{j}}{\sum_{k=0}^{2} \sum_{l=0}^{2} b_{k l}(T / \mathrm{K})^{k}(p / \mathrm{MPa})^{l}}$.

The values of the coefficients were calculated by means of a least-squares analysis of the experimental results (using the algorithm of Marquardt-Levenberg) and are given in table 2. The standard deviation between the experimental and fitted values is found to be $0.08 \%$ $(0.05 \%$ if solely the non-intrusive cell data are considered), which demonstrates the validity of this representation. This fitting equation was screened for thirty isotherms within the experimental temperature range $(265<T / \mathrm{K}<340)$, thus in steps of $2.5 \mathrm{~K}$, and for steps of $0.1 \mathrm{MPa}$ within the experimental interval of pressure $(0.1<p / \mathrm{MPa}<160)$ for a total of 48,000 data points. No poles for this rational function were found. Also, neither the temperature nor the pressure derivatives of $u(p, T)$ as described by equation (3) present any anomalies. Therefore, equation (3) can be safely used for interpolations.

As mentioned above, the only available experimental data on the pressure dependence of the speed of sound are those published 40 years ago by Eden and Richardson [10]. The comparison of their results with ours, presented for selected isotherms (figure 6), shows bad agreement in the whole pressure range. One should notice that, at lower temperatures, somewhat better agreement is seen for higher pressure while, at higher temperatures, the compared results come closer for lower pressure. A comparison between our density data and theirs reveals similar trends. It is our contention that the analysis of both the speed of sound and density data suggests that their acetone samples certainly contained a non-negligible amount of water and this constitutes the main reason for the observed discrepancies. There exists another single datum point for the speed of sound of acetone reported by Papaionnou et al. [21] at $298.15 \mathrm{~K}$ and $0.1 \mathrm{MPa}\left(u=1160.6 \mathrm{~m} \cdot \mathrm{s}^{-1}\right)$, which agrees reasonably well with our result $\left(u=1153.7 \mathrm{~m} \cdot \mathrm{s}^{-1}\right)$, but not sufficiently, taking into account our interval of uncertainty. Similarly, we attribute this discrepancy to a higher water content of the literature's sample.

The isothermal plots of the speed of sound versus pressure, shown in figure 3, are not linear showing, instead, obvious curvature, which becomes especially pronounced at higher temperatures. This fact suggests the proximity of the mechanical spinodal line (at which, theoretically, $u=0$ ). Below a certain temperature, which is system-to-system dependent, pure substances present a spinodal line for the liquid phase that is located at absolute negative pressures [25]. Negative pressure regimes can be achieved experimentally when the liquid probes metastable conditions of superheated and stretched states [26-28]. The spinodal line can be estimated using the Peng-Robinson equation of state (in the case of acetone, at $T=338 \mathrm{~K}$ it is found at $p=-32.5 \mathrm{MPa}$ ).

Density raw data as a function of both temperature and pressure are reported in table 3. Our experimental densities agree very well with existing, if scattered, literature data [12-14,21]. If one compares the collected literature data [12-14,21], with the results obtained in this work using a global fitting procedure (see equation (5) and table 4), one concludes that the agreement is better than $0.02 \%, 0.07 \%, 0.37 \%$, and $0.06 \%$, respectively. Although the global fitting procedure works very well for the representation of the density values, the differentiation with respect to $p$ and $T$ leads to some irregularities. Therefore, in order to calculate the isothermal compressibility, $\kappa_{\mathrm{T}}$, and the isobaric thermal expansivity, $\alpha_{\mathrm{p}}$, from $\rho(p, T)$ data we have decided to follow specific routes. To calculate the isothermal compressibility, $\kappa_{\mathrm{T}}$,

$\kappa_{\mathrm{T}}=\frac{1}{\rho}\left(\frac{\partial \rho}{\partial p}\right)_{\mathrm{T}}$

we used the well defined pressure dependence of density described by the Tait equation for each isotherm:

$1 / \rho=1 / \rho^{*}+A \ln \{(B+0.1) /(B+p)\}$, 
TABLE 1

Experimental speeds of sound $u$ for acetone as a function of temperature $T$ and pressure $p$

\begin{tabular}{|c|c|c|c|c|c|}
\hline$p / \mathrm{MPa}$ & $u /\left(\mathrm{m} \cdot \mathrm{s}^{-1}\right)$ & $p / \mathrm{MPa}$ & $u /\left(\mathrm{m} \cdot \mathrm{s}^{-1}\right)$ & $p / \mathrm{MPa}$ & $u /\left(\mathrm{m} \cdot \mathrm{s}^{-1}\right)$ \\
\hline \multicolumn{2}{|c|}{$T=265.67 \mathrm{~K}$} & 60.002 & 1520.08 & 34.997 & 1373.83 \\
\hline 0.102 & 1298.93 & 65.000 & 1538.71 & 39.999 & 1395.08 \\
\hline 0.504 & 1301.09 & \multirow{2}{*}{\multicolumn{2}{|c|}{$T=280.74 \mathrm{~K}$}} & 44.976 & $1418.48^{*}$ \\
\hline 0.750 & 1302.50 & & & 45.002 & 1416.10 \\
\hline 1.003 & 1303.56 & 0.075 & 1233.63 & 49.999 & 1435.37 \\
\hline 1.255 & 1304.92 & 0.075 & 1232.04 & 55.001 & 1453.97 \\
\hline 1.501 & 1306.29 & 0.504 & 1234.94 & 60.002 & 1473.72 \\
\hline 2.007 & 1308.73 & 0.750 & 1236.39 & 64.986 & $1494.63^{*}$ \\
\hline 2.506 & 1311.28 & 1.003 & 1237.85 & 65.000 & 1492.08 \\
\hline 3.005 & 1313.79 & 1.255 & 1239.22 & 70.010 & 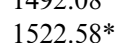 \\
\hline 4.004 & 1318.59 & 1.501 & 1240.59 & 79.981 & $\begin{array}{l}1522.50 \\
1557.72 *\end{array}$ \\
\hline 5.004 & 1323.31 & 2.007 & 1243.75 & $\begin{array}{l}19.981 \\
89.921\end{array}$ & $159143 *$ \\
\hline 6.005 & 1328.01 & 2.506 & 1247.03 & $\begin{array}{l}89.921 \\
99.957\end{array}$ & $\begin{array}{l}1591.43^{*} \\
162180 *\end{array}$ \\
\hline 8.002 & 1338.69 & 3.005 & 1249.76 & $\begin{array}{r}99.951 \\
109936\end{array}$ & $\begin{array}{l}1621.80^{*} \\
165070^{*}\end{array}$ \\
\hline 10.001 & 1349.81 & 4.004 & 1255.13 & $\begin{array}{l}109.936 \\
110980\end{array}$ & $\begin{array}{l}1650 . / 0^{*} \\
1680.46 *\end{array}$ \\
\hline 12.001 & 1358.70 & 5.004 & 1259.87 & 119.980 & $1680.46^{*}$ \\
\hline 14.003 & 1366.48 & 6.005 & 1264.80 & 129.872 & $1708.01^{*}$ \\
\hline 16.05 & $\begin{array}{l}1500.40 \\
1375.48\end{array}$ & 8.002 & 1275.79 & 139.915 & $1741.66^{*}$ \\
\hline 18.001 & 1384.77 & 10.001 & 1286.82 & 149.867 & $1768.25^{*}$ \\
\hline 18.001 & 1384.54 & 12.001 & 1296.79 & 159.874 & $1794.07^{*}$ \\
\hline 20.003 & $\begin{array}{l}1384.54 \\
1394.13\end{array}$ & 14.003 & 1306.71 & & \\
\hline 23.001 & $\begin{array}{l}1394.15 \\
1407.08\end{array}$ & 16.005 & 1316.23 & \multicolumn{2}{|c|}{$T=298.23 \mathrm{~K}$} \\
\hline 27.004 & $\begin{array}{l}1407.08 \\
1425.32\end{array}$ & 18.001 & 1325.46 & 0.109 & 1153.69 \\
\hline 31.003 & $\begin{array}{l}1425.32 \\
1439.78\end{array}$ & 20.003 & 1335.09 & 0.162 & $1155.53^{*}$ \\
\hline 34.997 & $\begin{array}{l}1439.78 \\
1455.17\end{array}$ & 23.001 & 1350.80 & 0.504 & 1156.23 \\
\hline 39.999 & $\begin{array}{l}1455.17 \\
1476.05\end{array}$ & 23.001 & $\begin{array}{l}1530.80 \\
1350.80\end{array}$ & 0.750 & 1157.82 \\
\hline 45.002 & $\begin{array}{l}1476.05 \\
1494.61\end{array}$ & 27.004 & $\begin{array}{l}1350.80 \\
1366.99\end{array}$ & 1.003 & 1159.50 \\
\hline 49.999 & $\begin{array}{l}1494.61 \\
1511.60\end{array}$ & 31.003 & $\begin{array}{l}1366.99 \\
1384.26\end{array}$ & 1.255 & 1161.14 \\
\hline 55.001 & $\begin{array}{l}1511.60 \\
1528.77\end{array}$ & 34.997 & $\begin{array}{l}1584.20 \\
1401.32\end{array}$ & 1.501 & 1162.71 \\
\hline 60.002 & $\begin{array}{l}1528.77 \\
1548.05\end{array}$ & 39.999 & 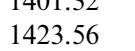 & 2.007 & 1165.65 \\
\hline 65.000 & $\begin{array}{l}1548.05 \\
1564.17\end{array}$ & 39.999 & $\begin{array}{l}1423.50 \\
1423.74\end{array}$ & 2.008 & $1167.09^{*}$ \\
\hline & 1564.17 & 45.002 & 1441.37 & 2.506 & 1168.60 \\
\hline & & 45.002 & 1441.37 & 3.005 & 1171.49 \\
\hline & & 49.999 & 1461.28 & 4.004 & 1177.40 \\
\hline 0.102 & 1264.48 & 55.001 & 1480.44 & 4.938 & $1185.79 *$ \\
\hline 0.504 & 1266.57 & 60.002 & $\begin{array}{l}1400.44 \\
1498.97\end{array}$ & 5.004 & 1182.90 \\
\hline 0.750 & 1267.96 & $\begin{array}{l}00.002 \\
60.002\end{array}$ & 1498.91 & 6.005 & 1189.60 \\
\hline 1.003 & 1269.39 & $\begin{array}{l}00.002 \\
65.000\end{array}$ & $\begin{array}{l}1498.91 \\
1514.56\end{array}$ & 8.002 & 1201.45 \\
\hline 1.255 & 1270.74 & $\begin{array}{l}65.000 \\
65.000\end{array}$ & $\begin{array}{l}1514.56 \\
1514.63\end{array}$ & 10.001 & 1212.80 \\
\hline 1.501 & 1272.23 & & & 12.001 & 1223.83 \\
\hline 2.007 & 1275.12 & \multicolumn{2}{|c|}{$T=288.23 \mathrm{~K}$} & 14.003 & 1234.83 \\
\hline 2.506 & 1277.93 & 0.109 & 1199.01 & 16.005 & 1246.18 \\
\hline 3.005 & 1281.10 & 0.504 & 1201.24 & 18.001 & 1256.46 \\
\hline 3.005 & 1281.19 & 0.750 & 1202.57 & 20.003 & 1265.92 \\
\hline 4.004 & 1287.23 & 1.003 & 1204.20 & 20.019 & $1268.46^{*}$ \\
\hline 4.004 & 1286.78 & 1.255 & 1205.54 & 23.001 & 1281.93 \\
\hline 5.004 & 1291.97 & 1.501 & 1206.97 & 27.004 & 1301.17 \\
\hline 5.004 & 1292.02 & 2.007 & 1209.92 & 31.003 & 1319.28 \\
\hline 6.005 & 1296.60 & 2.506 & 1212.80 & 34.997 & 1337.90 \\
\hline 8.002 & 1306.58 & 3.005 & 1215.61 & 39.999 & 1359.25 \\
\hline 10.001 & 1316.19 & 4.004 & 1221.35 & 45.002 & 1380.44 \\
\hline 12.001 & 1325.58 & 5.004 & 1227.14 & 49.999 & 1400.61 \\
\hline 14.003 & 1335.90 & 6.005 & 1232.71 & 55.001 & 1421.32 \\
\hline 16.005 & 1346.87 & 8.002 & 1244.39 & 60.002 & 1439.68 \\
\hline 18.001 & 1355.99 & 10.001 & 1255.40 & 65.000 & 1458.59 \\
\hline 20.003 & 1363.63 & 12.001 & 1265.22 & 65.010 & $1461.13^{*}$ \\
\hline 23.001 & 1376.52 & 14.003 & 1275.63 & 69.929 & $1479.73^{*}$ \\
\hline 27.004 & 1394.61 & 16.005 & 1286.61 & 79.828 & $1515.66^{*}$ \\
\hline 31.003 & 1412.24 & 18.001 & 1296.18 & 89.866 & $1549.26^{*}$ \\
\hline 34.997 & 1428.86 & 20.003 & 1305.89 & 99.836 & $1580.68^{*}$ \\
\hline 39.999 & 1446.67 & 23.001 & 1319.61 & 109.920 & $1612.39 *$ \\
\hline 45.002 & 1467.44 & 23.004 & $1322.04 *$ & 119.896 & $1641.11^{*}$ \\
\hline 49.999 & 1485.84 & 27.004 & 1339.05 & 129.797 & $1668.29 *$ \\
\hline 55.001 & 1504.31 & 31.003 & 1357.37 & 139.882 & $1695.55^{*}$ \\
\hline
\end{tabular}


TABLE 1 (continued)

\begin{tabular}{|c|c|c|c|c|c|}
\hline$p / \mathrm{MPa}$ & $u /\left(\mathrm{m} \cdot \mathrm{s}^{-1}\right)$ & $p / \mathrm{MPa}$ & $u /\left(\mathrm{m} \cdot \mathrm{s}^{-1}\right)$ & $p / \mathrm{MPa}$ & $u /\left(\mathrm{m} \cdot \mathrm{s}^{-1}\right)$ \\
\hline 149.849 & $1721.56^{*}$ & 10.001 & 1129.13 & 60.002 & 1345.81 \\
\hline 159.838 & $1743.99 *$ & 12.001 & 1142.47 & 64.927 & $1365.71 *$ \\
\hline & & 14.003 & 1154.62 & 65.000 & 1365.57 \\
\hline & & 16.005 & 1166.43 & 70.016 & $1390.37 *$ \\
\hline 0.109 & 1107.74 & 18.001 & 1177.61 & 79.971 & $1428.58 *$ \\
\hline 0.504 & 1110.52 & 18.039 & $1180.82 *$ & 89.947 & $1463.95^{*}$ \\
\hline 0.750 & 1112.35 & 20.003 & 1189.14 & 99.925 & $1498.01 *$ \\
\hline 1.003 & 1114.01 & 23.001 & 1205.63 & 109.933 & $1530.79 *$ \\
\hline 1.255 & 1115.75 & 27.004 & 1226.77 & 120.024 & $1561.93 *$ \\
\hline 1.501 & 1117.34 & 31.003 & 1247.41 & 129.885 & $1591.12 *$ \\
\hline 1.529 & $1120.00^{*}$ & 34.997 & 1266.28 & 139.921 & $1619.83^{*}$ \\
\hline 2.007 & 1120.69 & 35.013 & $1270.18^{*}$ & 149.939 & $1647.27 *$ \\
\hline 2.506 & 1123.91 & 39.999 & 1290.76 & 159.881 & $1673.62 *$ \\
\hline 3.005 & 1127.11 & 45.002 & 1313.78 & 107.001 & 1013.02 \\
\hline 4.004 & 1133.79 & 49.984 & $1336.94^{*}$ & \multicolumn{2}{|c|}{$T=338.22 \mathrm{~K}$} \\
\hline 5.004 & 1140.56 & 49.999 & 1334.83 & 0.170 & 972.80 \\
\hline 6.005 & 1146.98 & 55.001 & 1356.46 & 0.504 & 976.32 \\
\hline 8.002 & 1159.51 & 60.002 & 1376.77 & 0.750 & 978.88 \\
\hline 10.001 & 1171.13 & 64.915 & 1398.03* & 1.003 & 981.05 \\
\hline 12.001 & 1182.37 & 65.000 & 1395.43 & 1.255 & 982.97 \\
\hline 14.003 & 1194.75 & 69.945 & $1418.97 *$ & 1.501 & 984.75 \\
\hline 16.005 & 1205.76 & 79.995 & $1455.81^{*}$ & 2.007 & 988.42 \\
\hline 17.995 & $1218.24^{*}$ & 89.950 & $1490.61 *$ & 2.506 & 992.07 \\
\hline 18.001 & 1216.57 & $\begin{array}{r}89.950 \\
100.047\end{array}$ & $1524.64 *$ & 3.005 & 996.00 \\
\hline 20.003 & 1227.49 & $\begin{array}{l}100.04 / \\
109.858\end{array}$ & $1555.20 *$ & 4.004 & 1004.26 \\
\hline 23.001 & 1244.05 & $\begin{array}{l}109.858 \\
119.927\end{array}$ & $1585.72 *$ & 5.004 & 1011.63 \\
\hline 27.004 & 1263.44 & 129.859 & $1614.28 *$ & 5.007 & $1009.07^{*}$ \\
\hline 31.003 & 1283.97 & 139.873 & $1642.01 *$ & 6.005 & 1019.16 \\
\hline 34.970 & $1305.89 *$ & 149.838 & $1668.21 *$ & 8.002 & 1033.34 \\
\hline 34.997 & 1302.46 & 159.857 & $1694.12 *$ & 10.001 & 1047.72 \\
\hline 39.999 & 1324.45 & $159.85 /$ & $1694.12^{*}$ & 12.001 & 1061.19 \\
\hline 45.002 & 1347.09 & \multicolumn{2}{|c|}{$T=328.22 \mathrm{~K}$} & 14.003 & 1074.71 \\
\hline 49.966 & $1370.35^{*}$ & 0.129 & 1018.30 & 16.005 & 1088.09 \\
\hline 49.999 & 1367.79 & 0.504 & 1021.14 & 18.001 & 1100.33 \\
\hline 55.001 & 1388.31 & 0.750 & 1023.10 & 19.962 & $1112.67^{*}$ \\
\hline 60.002 & 1408.07 & 1.003 & 1024.91 & 20.003 & 1112.58 \\
\hline 64.978 & $1431.07^{*}$ & 1.255 & 1026.82 & 20.078 & $1113.05^{*}$ \\
\hline 65.000 & 1427.73 & 1.279 & $1026.65^{*}$ & 23.001 & 1131.02 \\
\hline 69.913 & $1448.08^{*}$ & 1.501 & 1028.60 & 27.004 & 1154.76 \\
\hline 80.042 & $1484.54 *$ & 2.007 & 1032.33 & 31.003 & 1176.19 \\
\hline 89.948 & $1517.17^{*}$ & 2.506 & 1036.21 & 34.862 & $1200.01 *$ \\
\hline 100.008 & $1550.07^{*}$ & 3.005 & 1040.05 & 34.997 & 1197.57 \\
\hline 109.959 & $1580.84^{*}$ & 4.004 & 1047.07 & 35.061 & $1200.11^{*}$ \\
\hline 120.002 & $1610.69^{*}$ & 5.004 & 1053.76 & 39.999 & 1223.29 \\
\hline 129.943 & $1638.63^{*}$ & 6.005 & 1060.70 & 45.002 & 1248.14 \\
\hline 139.970 & $1665.32 *$ & 8.002 & 1074.73 & 49.999 & 1271.19 \\
\hline 149.805 & $1691.77^{*}$ & 10.001 & 1088.42 & 54.993 & $1290.41^{*}$ \\
\hline 159.981 & $1714.52 *$ & 10.021 & $1088.58^{*}$ & 55.001 & 1293.31 \\
\hline \multirow{2}{*}{\multicolumn{2}{|c|}{$T=318.22 \mathrm{~K}$}} & 12.001 & 1101.14 & 55.162 & $1290.99 *$ \\
\hline & & 14.003 & 1113.97 & 60.002 & 1315.39 \\
\hline 0.109 & 1062.32 & 16.005 & 1126.49 & 64.959 & $1338.94 *$ \\
\hline 0.504 & 1065.38 & 18.001 & 1138.92 & 65.000 & 1336.38 \\
\hline 0.750 & 1067.34 & 20.003 & 1151.08 & 65.100 & $1339.48^{*}$ \\
\hline 1.003 & 1069.21 & 23.001 & 1168.10 & 70.004 & $1360.20 *$ \\
\hline 1.255 & 1071.11 & 26.986 & $1189.14 *$ & 80.065 & $1399.97 *$ \\
\hline 1.501 & 1072.72 & 27.004 & 1190.45 & 89.970 & $1437.71 *$ \\
\hline 2.007 & 1076.32 & 31.003 & 1211.66 & 99.933 & $1472.23 *$ \\
\hline 2.506 & 1079.71 & 34.997 & 1231.66 & 109.905 & $1505.88^{*}$ \\
\hline 3.005 & 1083.50 & 39.941 & $1258.02 *$ & 119.873 & $1538.58 *$ \\
\hline 4.004 & 1090.38 & 39.999 & 1256.67 & 129.936 & $1569.69 *$ \\
\hline 5.004 & 1096.85 & 45.002 & 1280.63 & 139.985 & $1599.90 *$ \\
\hline 5.049 & $1100.00^{*}$ & 49.999 & 1303.34 & 149.899 & $1628.37^{*}$ \\
\hline 6.005 & 1103.61 & $\begin{array}{l}49.999 \\
55.001\end{array}$ & 1324.67 & 159.818 & $1656.51^{*}$ \\
\hline 8.002 & 1116.61 & & & & 1050.01 \\
\hline
\end{tabular}

*Measurements performed with the non-intrusive method. 
TABLE 2

Coefficients of equation (3) valid within the intervals: $265<T$ / $\mathrm{K}<340$ and $0.1<p / \mathrm{MPa}<160$

\begin{tabular}{lccc}
\hline$a_{i j}$ & \multicolumn{3}{c}{$j$} \\
\cline { 2 - 4 }$i$ & 0 & 1 & 2 \\
\hline 0 & $2.55504 \cdot 10^{3}$ & $4.28692 \cdot 10^{1}$ & -2.20070 \\
1 & -8.34018 & $-3.19580 \cdot 10^{-1}$ & $1.28060 \cdot 10^{-2}$ \\
2 & $6.31423 \cdot 10^{-3}$ & $7.35340 \cdot 10^{-4}$ & $-1.76633 \cdot 10^{-5}$ \\
$b_{k l}$ & & $l$ & \\
\cline { 2 - 4 }$k$ & 0 & 1 & 2 \\
\hline 0 & 1.00000 & $6.32893 \cdot 10^{-2}$ & $-1.54202 \cdot 10^{-3}$ \\
1 & $-1.20021 \cdot 10^{-3}$ & $-5.01416 \cdot 10^{-4}$ & $9.37898 \cdot 10^{-6}$ \\
2 & $-1.08291 \cdot 10^{-6}$ & $1.06248 \cdot 10^{-6}$ & $-1.39463 \cdot 10^{-8}$ \\
\hline
\end{tabular}

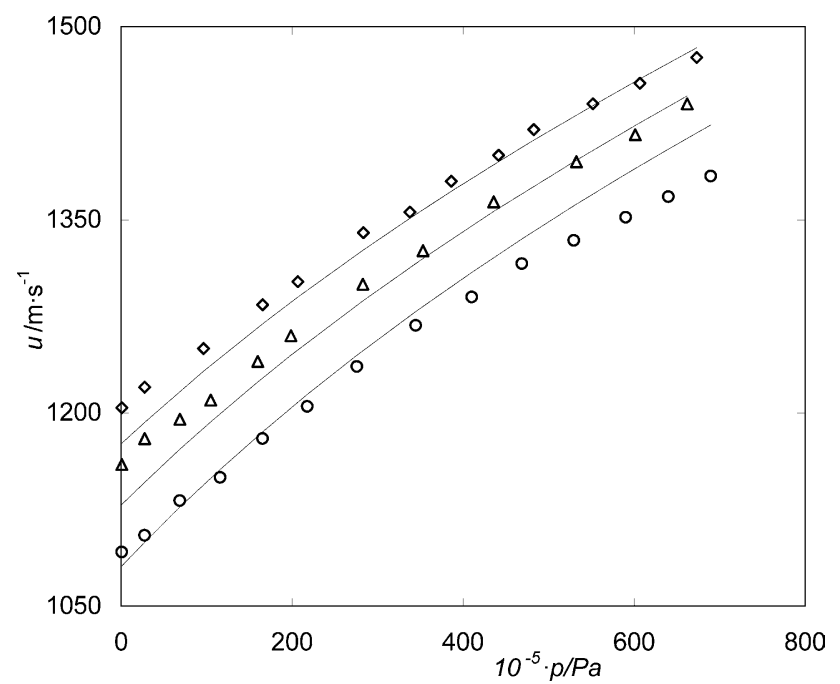

FIGURE 6. Comparison between our interpolated speed of sound data (full lines) for acetone using the Pade $3 \times 3$ fitting (equation (3)) and the data of Eden and Richardson [10]. $\bigcirc, 314.15 \mathrm{~K} ; \triangle, 303.65 \mathrm{~K}$; $\diamond, 293.15 \mathrm{~K}$.

where $\rho^{*}$ is the density at a given temperature and at a reference pressure of $0.1 \mathrm{MPa}$. The Tait equation has long proven to constitute a powerful fitting equation even in the low pressure region near orthobaric conditions [29], provided the pressure interval is not extremely broad. Dymond and Malhotra [30] discussed the merits of this equation and its excellent representation of liquid densities up to $150 \mathrm{MPa}$. Typically, in the current work, the largest residuals for each isotherm of density are of about $0.003 \%$. The coefficients of the fitting equation are given in table 4 . The calculated $\kappa_{\mathrm{T}}$ values for acetone are presented in figure 7 and table 5. Our values of $\kappa_{\mathrm{T}}$ compare well with those reported by Malhotra and Woolf [13] and Staveley et al. [23]. The deviations are not greater than $2 \%$.
The isobaric thermal expansivity, $\alpha_{\mathrm{p}}$, defined as:

$\alpha_{\mathrm{p}}=-\frac{1}{\rho}\left(\frac{\partial \rho}{\partial T}\right)_{\mathrm{p}}$

can also be obtained from analytical differentiation of the $\rho(T)$ fitting equation. Unfortunately, there is no analogue of the Tait equation for the temperature dependence. As shown above, many analytical fitting equations can satisfactorily reproduce the experimental densities but at the same time lead to different isobaric thermal expansion coefficients. Because the best choice of method for fitting the $\rho(T)$ data is unclear, several attempts were checked and it was finally decided to use a second order polynomial to individually fit each experimental isobar. The results of $\alpha_{\mathrm{p}}$ are presented in figure 8 and reported in table 6 . The agreement between our results and those from literature [13,23] is satisfactory over the whole temperature and pressure range studied deviations are not greater than 3\%.

Densities and speed of sound data can be combined to calculate the isentropic compressibility according to the equation:

$\kappa_{\mathrm{S}}=\frac{1}{u^{2} \rho}$.

The calculated isentropic compressibilities are presented in figure 9 and table 7. Estimated uncertainties are less than $1 \%$. Selected points can be compared with the available literature data $[21,23]$ at $0.1 \mathrm{MPa}$. The agreement is satisfactory, within $2 \%$.

The density and speed of sound data when combined lead to the calculation of isobaric heat capacities through the well known thermodynamic relation:

$c_{\mathrm{p}}=\frac{T}{\rho} \frac{\alpha_{\mathrm{p}}^{2}}{\kappa_{\mathrm{T}}-\kappa_{\mathrm{S}}}$.

In the calculation of isobaric heat capacities, all values for each thermodynamic property expressed in equation (8) were obtained as previously described. For instance, isothermal compressibilities were obtained by pressure differentiation of equation (5), whereas isobaric thermal expansivities were obtained by temperature differentiation of second order polynomials that individually fit each experimental isobar of density (see table 8).

Although the present $c_{\mathrm{p}}$ data agree reasonably well with both reported calculated [13] and experimental [23] (calorimetric) values, the uncertainties associated with the calculated ones can be as high as $7 \%$. In the calculation of $c_{\mathrm{p}}$, all errors of the previously calculated quantities accumulate, and especially large errors may arise from the difference $\left(\kappa_{\mathrm{T}}-\kappa_{\mathrm{S}}\right)$. As for the latter, our results show that the ratio $\left(\kappa_{\mathrm{T}} / \kappa_{\mathrm{S}}\right)$ in acetone varies, irrespective of temperature, linearly from 1.4 to 1.3 as pressure shifts from ( 0.1 to 60$) \mathrm{MPa}$. In other words, $\kappa_{\mathrm{T}}$ is greater than $\kappa_{\mathrm{S}}$ by $30 \%$ to $40 \%$. Taking into account that the accuracy of both $\kappa_{\mathrm{T}}$ and $\kappa_{\mathrm{S}}$ is of the order of a 
TABLE 3

Experimental densities $\rho$ for acetone at temperatures $T$ and pressures $p$

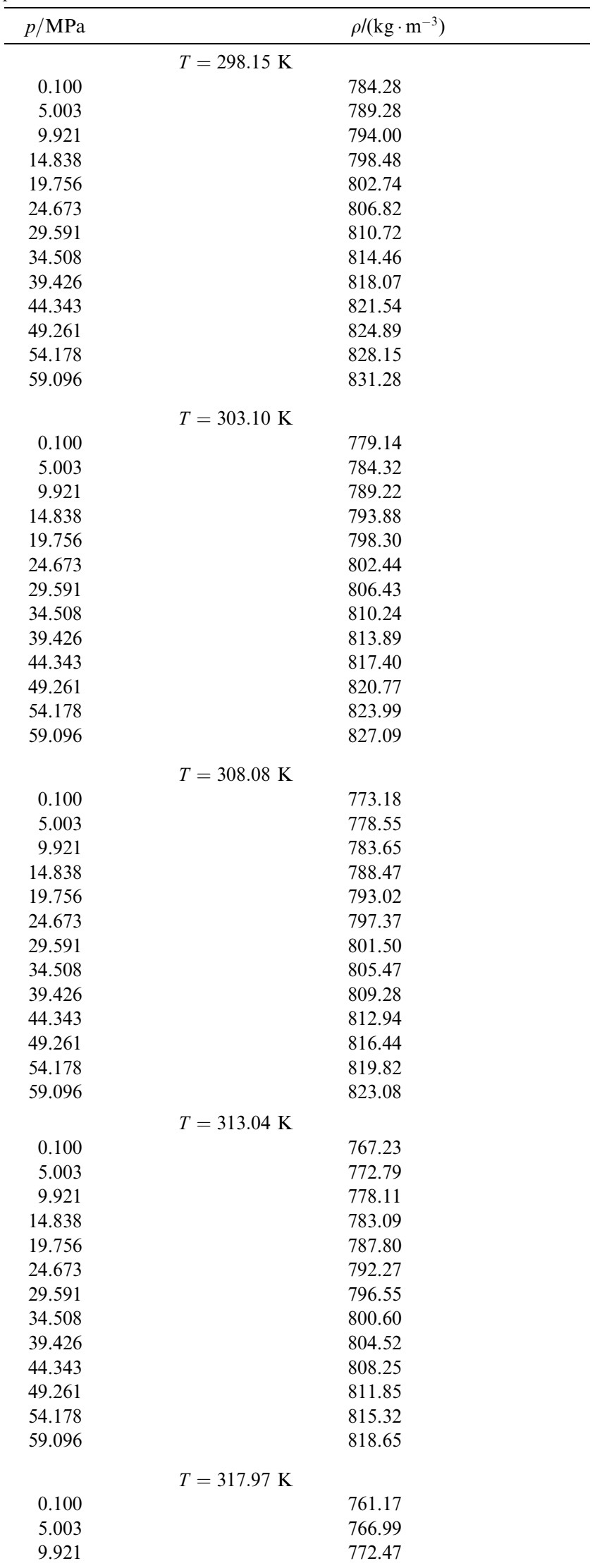

TABLE 3 (continued)

\begin{tabular}{|c|c|}
\hline$p / \mathrm{MPa}$ & $\rho /\left(\mathrm{kg} \cdot \mathrm{m}^{-3}\right)$ \\
\hline 14.838 & 777.62 \\
\hline 19.756 & 782.47 \\
\hline 24.673 & 787.11 \\
\hline 29.591 & 791.49 \\
\hline 34.508 & 795.70 \\
\hline 39.426 & 799.71 \\
\hline 44.343 & 803.57 \\
\hline 49.261 & 807.28 \\
\hline 54.178 & 810.82 \\
\hline \multirow[t]{2}{*}{59.096} & 814.24 \\
\hline & \\
\hline 0.100 & 755.22 \\
\hline 5.003 & 761.27 \\
\hline 9.921 & 766.95 \\
\hline 14.838 & 772.25 \\
\hline 19.756 & 777.28 \\
\hline 24.673 & 781.99 \\
\hline 29.591 & 786.54 \\
\hline 34.508 & 790.84 \\
\hline 39.426 & 795.02 \\
\hline 44.343 & 798.96 \\
\hline 49.261 & 802.75 \\
\hline 54.178 & 806.40 \\
\hline \multirow[t]{2}{*}{59.096} & 809.91 \\
\hline & \\
\hline 0.100 & 748.91 \\
\hline 5.003 & 755.20 \\
\hline 9.921 & 761.09 \\
\hline 14.838 & 766.61 \\
\hline 19.756 & 771.75 \\
\hline 24.673 & 776.65 \\
\hline 29.591 & 781.30 \\
\hline 34.508 & 785.72 \\
\hline 39.426 & 789.98 \\
\hline 44.343 & 794.04 \\
\hline 49.261 & 797.97 \\
\hline 54.178 & 801.71 \\
\hline \multirow[t]{2}{*}{59.096} & 805.36 \\
\hline & \\
\hline 5.003 & 749.27 \\
\hline 9.921 & 755.39 \\
\hline 14.838 & 761.07 \\
\hline 19.756 & 766.40 \\
\hline 24.673 & 771.41 \\
\hline 29.591 & 776.21 \\
\hline 34.508 & 780.78 \\
\hline 39.426 & 785.17 \\
\hline 44.343 & 789.33 \\
\hline 49.261 & 793.37 \\
\hline 54.178 & 797.25 \\
\hline 59.096 & 801.03 \\
\hline
\end{tabular}

few percent, the calculation of $c_{\mathrm{p}}$ based on equation (8) can still be legitimated, but the difference in the denominator largely contributes to the overall uncertainty of $c_{\mathrm{p}}$. Taking into account the relation:

$c_{\mathrm{p}} / c_{\mathrm{v}}=\kappa_{\mathrm{T}} / \kappa_{\mathrm{S}}$,

one can calculate the isochoric specific heat capacity according to: 
TABLE 4

Coefficients of equation (5) for the density of acetone on each isotherm, valid in the range $(0.1<p / \mathrm{MPa}<60)^{a}$

\begin{tabular}{llll}
\hline$T / \mathrm{K}$ & $A /\left(\mathrm{kg}^{-1} \cdot \mathrm{m}^{3}\right)$ & $B / \mathrm{MPa}$ & $\rho^{*} /\left(\mathrm{kg} \cdot \mathrm{m}^{-3}\right)$ \\
\hline 298.15 & $1.14838 \cdot 10^{-4}$ & 67.4822 & 784.332 \\
303.10 & $1.15333 \cdot 10^{-4}$ & 64.1469 & 778.763 \\
308.08 & $1.16241 \cdot 10^{-4}$ & 61.1206 & 773.039 \\
313.04 & $1.17553 \cdot 10^{-4}$ & 58.4346 & 767.217 \\
317.97 & $1.19261 \cdot 10^{-4}$ & 56.0893 & 761.310 \\
322.93 & $1.21386 \cdot 10^{-4}$ & 54.0563 & 755.247 \\
328.06 & $1.24012 \cdot 10^{-4}$ & 52.2982 & 748.849 \\
333.04 & $1.26979 \cdot 10^{-4}$ & 50.9265 & 742.514 \\
\hline
\end{tabular}

${ }^{a}$ In the case of global fitting procedure one uses $A=8.33473 \cdot 10^{-4}-4.87964 \cdot 10^{-6}(T / \mathrm{K})+8.28215 \cdot 10^{-9}(T / \mathrm{K})^{2}, \quad B=869.871-$ $4.67571(T / \mathrm{K})+6.65600 \cdot 10^{-3}(T / \mathrm{K})^{2}$, and $\rho^{*}=897.862+3.51327 \cdot 10^{-1}(T / \mathrm{K})-2.45551 \cdot 10^{-3}(T / \mathrm{K})^{2}$.

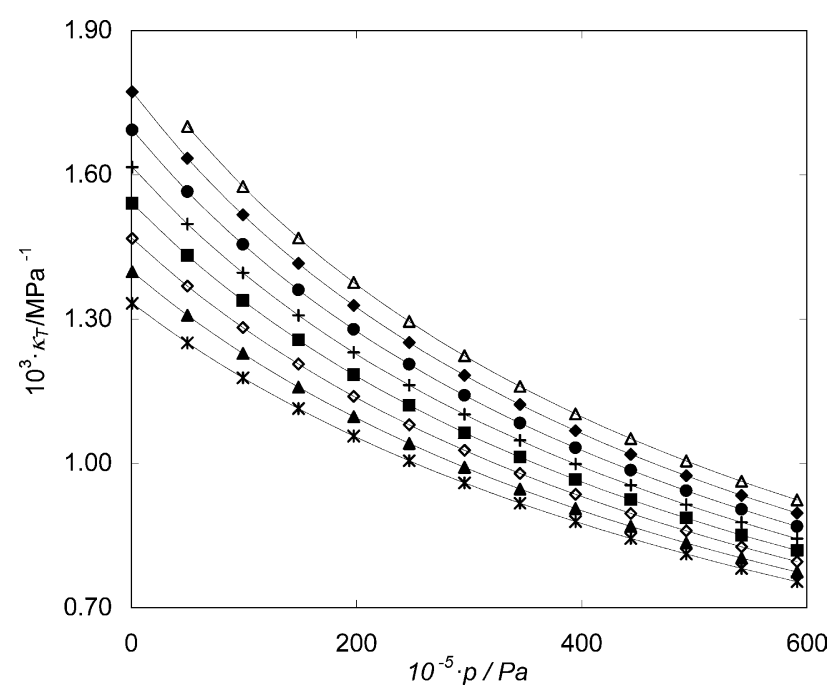

FIGURE 7. Isotherms for the isothermal compressibility of acetone. $\triangle, 333.04 \mathrm{~K} ; \diamond, 328.06 \mathrm{~K} ; \bullet, 322.93 \mathrm{~K} ;+, 317.97 \mathrm{~K} ; \mathbf{\square}, 313.04 \mathrm{~K} ; \diamond$, $308.08 \mathrm{~K} ; \boldsymbol{\Delta}, 303.10 \mathrm{~K} ; \boldsymbol{*}, 298.15 \mathrm{~K}$.

$$
c_{\mathrm{v}}=\frac{T}{\rho} \frac{\alpha_{\mathrm{p}}^{2} \kappa_{\mathrm{S}}}{\kappa_{\mathrm{T}}\left(\kappa_{\mathrm{T}}-\kappa_{\mathrm{S}}\right)} .
$$

Calculated values compare favourably (within $\sim 5 \%$ ) with those reported by Staveley et al. [23] for 0.1 MPa. Finally, it is worth to calculate values of the thermal pressure coefficient, $\gamma_{\mathrm{v}}$. According to the definition:

$\gamma_{\mathrm{v}}=\left(\frac{\partial p}{\partial T}\right)_{\mathrm{v}}=\frac{\alpha_{\mathrm{p}}}{\kappa_{\mathrm{T}}}$.

Calculated values are in good agreement with data reported by Staveley et al. [23] at $0.1 \mathrm{MPa}$ (within $\sim 3 \%$ ).

\section{Conclusions}

The values of calculated thermodynamic properties of acetone are generally in good agreement with the most reliable data found in the literature proving the high quality of the experimentally measured densities and speeds of sound. This, in turn, proves the usefulness of the new microcell for speed of sound measurements in broad temperature and pressure ranges.

TABLE 5

Calculated values of isothermal compressibility $\kappa_{\mathrm{T}}$ from this work on the experimental isotherms and isobars

\begin{tabular}{|c|c|c|c|c|c|c|c|c|}
\hline \multirow[t]{2}{*}{$p / \mathrm{MPa}$} & \multicolumn{8}{|l|}{$T / \mathrm{K}$} \\
\hline & 298.15 & 303.10 & 308.08 & 313.04 & 317.97 & 322.93 & 328.06 & 333.04 \\
\hline \multicolumn{9}{|c|}{$10^{3} \kappa_{\mathrm{T}} / \mathrm{MPa}^{-1}$} \\
\hline 0.100 & $1.33_{3}$ & $1.39_{8}$ & $1.46_{8}$ & $1.54_{1}$ & $1.61_{6}$ & $1.69_{3}$ & $1.77_{2}$ & \\
\hline 5.003 & $1.25_{0}$ & $1.30_{8}$ & $1.36_{8}$ & $1.43_{2}$ & $1.49_{8}$ & $1.56_{5}$ & $1.63_{4}$ & $1.70_{0}$ \\
\hline 9.921 & $1.17_{8}$ & $1.22_{8}$ & $1.28_{2}$ & $1.33_{8}$ & $1.39_{6}$ & $1.45_{5}$ & $1.51_{7}$ & $1.57_{6}$ \\
\hline 14.838 & $1.11_{4}$ & $1.15_{9}$ & $1.20_{6}$ & $1.25_{6}$ & $1.30_{8}$ & $1.36_{1}$ & $1.41_{6}$ & $1.46_{9}$ \\
\hline 19.756 & $1.05_{7}$ & $1.09_{7}$ & $1.14_{0}$ & $1.18_{4}$ & $1.23_{1}$ & $1.27_{8}$ & $1.32_{8}$ & $1.37_{6}$ \\
\hline 24.673 & $1.00_{5}$ & $1.04_{2}$ & $1.08_{0}$ & $1.12_{1}$ & $1.16_{3}$ & $1.20_{6}$ & $1.25_{1}$ & $1.29_{5}$ \\
\hline 29.591 & $0.95_{9}$ & $0.99_{2}$ & $1.02_{7}$ & $1.06_{4}$ & $1.10_{2}$ & $1.14_{1}$ & $1.18_{3}$ & $1.22_{4}$ \\
\hline 34.508 & $0.91_{7}$ & $0.94_{7}$ & $0.97_{9}$ & $1.01_{3}$ & $1.04_{8}$ & $1.08_{4}$ & $1.12_{2}$ & $1.16_{0}$ \\
\hline 39.426 & $0.87_{9}$ & $0.90_{6}$ & $0.93_{5}$ & $0.96_{6}$ & $0.99_{9}$ & $1.03_{2}$ & $1.06_{8}$ & $1.10_{3}$ \\
\hline 44.343 & $0.84_{4}$ & $0.86_{9}$ & $0.89_{6}$ & $0.92_{4}$ & $0.95_{4}$ & $0.98_{6}$ & $1.01_{9}$ & $1.05_{2}$ \\
\hline 49.261 & $0.81_{1}$ & $0.83_{5}$ & $0.86_{0}$ & $0.88_{6}$ & $0.91_{4}$ & $0.94_{3}$ & $0.97_{4}$ & $1.00_{5}$ \\
\hline 54.178 & $0.78_{2}$ & $0.80_{3}$ & $0.82_{6}$ & $0.85_{1}$ & $0.87_{7}$ & $0.90_{4}$ & $0.93_{4}$ & $0.96_{3}$ \\
\hline 59.096 & $0.75_{4}$ & $0.77_{4}$ & $0.79_{6}$ & $0.81_{9}$ & $0.84_{3}$ & $0.86_{9}$ & $0.89_{6}$ & $0.92_{4}$ \\
\hline
\end{tabular}




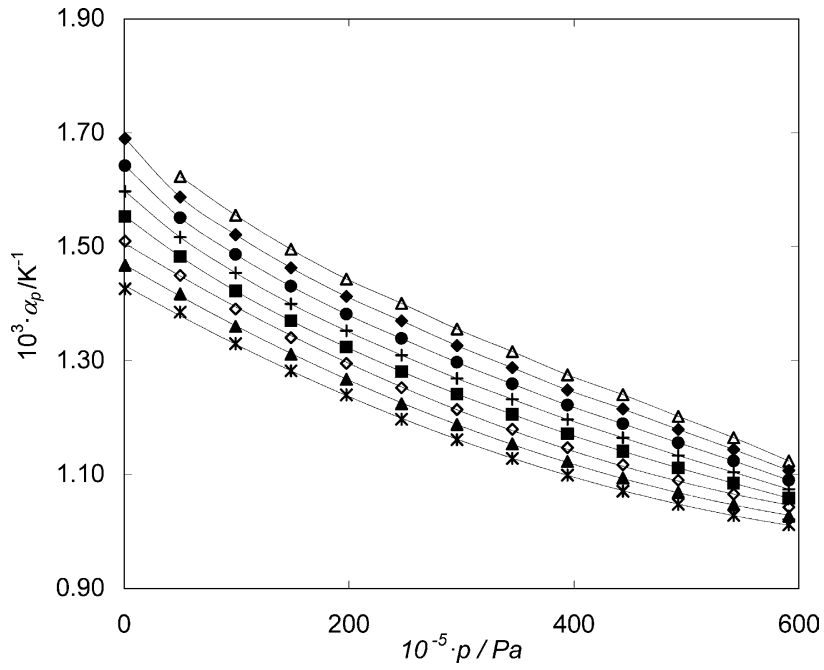

FIGURE 8. Isotherms for the isobaric expansivity of acetone. $\triangle$, $333.04 \mathrm{~K} ; \diamond, 328.06 \mathrm{~K} ; \bullet, 322.93 \mathrm{~K} ;+317.97 \mathrm{~K} ; \mathbf{\square}, 313.04 \mathrm{~K} ; \diamond$, $308.08 \mathrm{~K} ; \boldsymbol{\Delta}, 303.10 \mathrm{~K} ; \boldsymbol{*}, 298.15 \mathrm{~K}$.

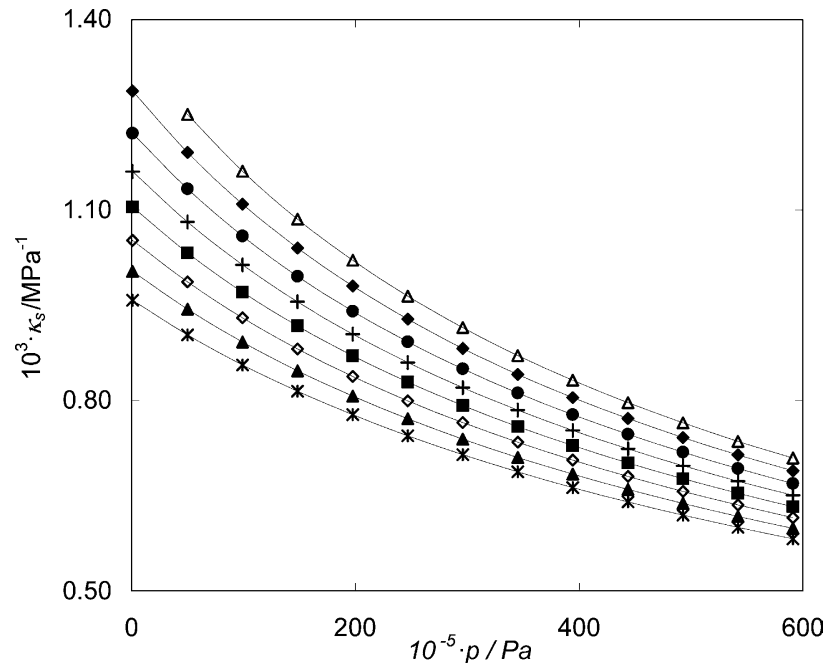

FIGURE 9. Isotherms for the isentropic compressibility of acetone. $\triangle$, $333.04 \mathrm{~K} ; \diamond, 328.06 \mathrm{~K} ; \bullet$ •, $322.93 \mathrm{~K} ;+, 317.97 \mathrm{~K} ; \mathbf{\square}, 313.04 \mathrm{~K} ; \diamond$, $308.08 \mathrm{~K} ; \boldsymbol{\Lambda}, 303.10 \mathrm{~K} ; \boldsymbol{*}, 298.15 \mathrm{~K}$.

TABLE 6

Calculated values of isobaric thermal expansivity $\alpha_{\mathrm{p}}$ from this work on the experimental isotherms and isobars

\begin{tabular}{|c|c|c|c|c|c|c|c|c|}
\hline \multirow[t]{2}{*}{$p / \mathrm{MPa}$} & \multicolumn{8}{|l|}{$T / \mathrm{K}$} \\
\hline & 298.15 & 303.10 & 308.08 & 313.04 & 317.97 & 322.93 & 328.06 & 333.04 \\
\hline \multicolumn{9}{|c|}{$10^{3} \alpha_{\mathrm{p}} / \mathrm{K}^{-1}$} \\
\hline 0.100 & $1.42_{6}$ & $1.46_{7}$ & $1.51_{0}$ & $1.55_{3}$ & $1.59_{7}$ & $1.64_{2}$ & $1.68_{9}$ & \\
\hline 5.003 & $1.38_{5}$ & $1.41_{7}$ & $1.44_{9}$ & $1.48_{2}$ & $1.51_{6}$ & $1.55_{1}$ & $1.58_{7}$ & $1.62_{3}$ \\
\hline 9.921 & 1.329 & $1.36_{0}$ & $1.39_{1}$ & $1.42_{2}$ & $1.45_{4}$ & $1.48_{6}$ & $1.52_{1}$ & $1.55_{5}$ \\
\hline 14.838 & $1.28_{2}$ & $1.31_{1}$ & $1.34_{0}$ & $1.36_{9}$ & $1.40_{0}$ & $1.43_{0}$ & $1.46_{3}$ & $1.49_{5}$ \\
\hline 19.756 & $1.24_{0}$ & $1.26_{7}$ & $1.29_{5}$ & $1.32_{3}$ & $1.35_{2}$ & $1.38_{1}$ & $1.41_{2}$ & $1.44_{3}$ \\
\hline 24.673 & $1.19_{7}$ & $1.22_{4}$ & $1.25_{2}$ & $1.28_{1}$ & $1.30_{9}$ & $1.33_{9}$ & $1.37_{0}$ & $1.40_{0}$ \\
\hline 29.591 & $1.16_{1}$ & $1.18_{7}$ & $1.21_{4}$ & $1.24_{1}$ & $1.26_{9}$ & $1.29_{7}$ & $1.32_{6}$ & $1.35_{5}$ \\
\hline 34.508 & $1.12_{8}$ & $1.15_{3}$ & $1.17_{9}$ & $1.20_{6}$ & $1.23_{2}$ & $1.25_{9}$ & $1.28_{7}$ & $1.31_{6}$ \\
\hline 39.426 & $1.09_{9}$ & $1.12_{3}$ & $1.14_{7}$ & $1.17_{1}$ & $1.19_{6}$ & $1.22_{2}$ & $1.24_{8}$ & $1.27_{5}$ \\
\hline 44.343 & $1.07_{1}$ & $1.09_{4}$ & $1.11_{7}$ & $1.14_{1}$ & $1.16_{5}$ & 1.189 & $1.21_{5}$ & $1.24_{0}$ \\
\hline 49.261 & $1.04_{7}$ & $1.06_{8}$ & $1.09_{0}$ & $1.11_{1}$ & $1.13_{3}$ & $1.15_{5}$ & $1.17_{9}$ & $1.20_{2}$ \\
\hline 54.178 & $1.02_{8}$ & $1.04_{7}$ & $1.06_{5}$ & $1.08_{5}$ & $1.10_{4}$ & $1.12_{3}$ & $1.14_{4}$ & $1.16_{4}$ \\
\hline 59.096 & $1.01_{2}$ & $1.02_{7}$ & $1.04_{3}$ & $1.05_{8}$ & $1.07_{4}$ & $1.09_{0}$ & $1.10_{7}$ & $1.12_{4}$ \\
\hline
\end{tabular}

TABLE 7

Calculated values of isentropic compressibility $\kappa_{\mathrm{s}}$ from this work on the experimental isotherms and isobars

\begin{tabular}{|c|c|c|c|c|c|c|c|c|}
\hline \multirow[t]{2}{*}{$p / \mathrm{MPa}$} & \multicolumn{8}{|l|}{$T / \mathrm{K}$} \\
\hline & 298.15 & 303.10 & 308.08 & 313.04 & 317.97 & 322.93 & 328.06 & 333.04 \\
\hline \multicolumn{9}{|c|}{$10^{3} \kappa_{\mathrm{s}} / \mathrm{MPa}^{-1}$} \\
\hline 0.100 & $0.95_{8}$ & $1.00_{3}$ & $1.05_{2}$ & $1.10_{5}$ & $1.16_{0}$ & $1.22_{1}$ & $1.28_{7}$ & \\
\hline 5.003 & $0.90_{3}$ & $0.94_{4}$ & $0.98_{7}$ & $1.03_{3}$ & $1.08_{1}$ & $1.13_{3}$ & $1.19_{1}$ & $1.25_{0}$ \\
\hline 9.921 & $0.85_{6}$ & $0.89_{2}$ & $0.93_{0}$ & $0.97_{1}$ & $1.01_{3}$ & $1.05_{9}$ & $1.10_{9}$ & $1.16_{1}$ \\
\hline 14.838 & $0.81_{4}$ & $0.84_{7}$ & $0.88_{1}$ & $0.91_{7}$ & $0.95_{5}$ & $0.99_{6}$ & $1.04_{0}$ & $1.08_{5}$ \\
\hline 19.756 & $0.77_{8}$ & $0.80_{7}$ & $0.83_{8}$ & $0.87_{0}$ & $0.90_{5}$ & $0.94_{1}$ & $0.98_{0}$ & $1.02_{1}$ \\
\hline 24.673 & $0.74_{4}$ & $0.77_{1}$ & $0.79_{9}$ & $0.82_{9}$ & $0.86_{0}$ & $0.89_{3}$ & $0.92_{8}$ & $0.96_{4}$ \\
\hline 29.591 & $0.71_{5}$ & $0.73_{9}$ & $0.76_{5}$ & $0.79_{2}$ & $0.82_{0}$ & $0.85_{0}$ & $0.88_{2}$ & $0.91_{5}$ \\
\hline 34.508 & $0.68_{8}$ & $0.71_{0}$ & $0.73_{4}$ & $0.75_{9}$ & $0.78_{5}$ & $0.81_{2}$ & $0.84_{1}$ & $0.87_{1}$ \\
\hline 39.426 & $0.66_{3}$ & $0.68_{4}$ & $0.70_{6}$ & $0.72_{9}$ & $0.75_{3}$ & $0.77_{8}$ & $0.80_{4}$ & $0.83_{2}$ \\
\hline 44.343 & $0.64_{0}$ & $0.66_{0}$ & $0.68_{1}$ & $0.70_{2}$ & $0.72_{4}$ & $0.74_{7}$ & $0.77_{1}$ & $0.79_{7}$ \\
\hline 49.261 & $0.62_{0}$ & $0.63_{8}$ & $0.65_{7}$ & $0.67_{7}$ & $0.69_{7}$ & $0.71_{9}$ & $0.74_{2}$ & $0.76_{5}$ \\
\hline 54.178 & $0.60_{0}$ & $0.61_{8}$ & $0.63_{5}$ & $0.65_{4}$ & $0.67_{3}$ & $0.69_{3}$ & $0.71_{4}$ & $0.73_{6}$ \\
\hline 59.096 & $0.58_{2}$ & $0.59_{9}$ & $0.61_{6}$ & $0.63_{3}$ & $0.65_{1}$ & $0.66_{9}$ & $0.68_{9}$ & $0.70_{9}$ \\
\hline
\end{tabular}


TABLE 8

Calculated values of isobaric specific heat capacity $c_{\mathrm{p}}$ from this work on the experimental isotherms and isobars

\begin{tabular}{|c|c|c|c|c|c|c|c|c|}
\hline \multirow[t]{2}{*}{$p / \mathrm{MPa}$} & \multicolumn{8}{|l|}{$T / \mathrm{K}$} \\
\hline & 298.15 & 303.10 & 308.08 & 313.04 & 317.97 & 322.93 & 328.06 & 333.04 \\
\hline \multicolumn{9}{|c|}{$c_{\mathrm{p}} /\left(\mathrm{kJ} \cdot \mathrm{kg}^{-1} \cdot \mathrm{K}^{-1}\right)$} \\
\hline 0.100 & $2.04_{4}$ & $2.09_{7}$ & $2.15_{1}$ & $2.21_{2}$ & $2.28_{3}$ & $2.36_{7}$ & $2.49_{3}$ & \\
\hline 5.003 & $2.04_{8}$ & $2.10_{3}$ & $2.15_{9}$ & $2.21_{9}$ & $2.28_{8}$ & $2.36_{8}$ & $2.48_{9}$ & $2.59_{7}$ \\
\hline 9.921 & $2.05_{2}$ & $2.10_{9}$ & $2.16_{6}$ & $2.22_{6}$ & $2.29_{4}$ & $2.36_{9}$ & $2.48_{4}$ & 2.589 \\
\hline 14.838 & $2.05_{6}$ & $2.11_{5}$ & $2.17_{3}$ & $2.23_{3}$ & $2.29_{9}$ & $2.37_{0}$ & $2.48_{0}$ & $2.58_{1}$ \\
\hline 19.756 & $2.06_{0}$ & $2.12_{1}$ & $2.18_{1}$ & $2.24_{0}$ & $2.30_{5}$ & $2.37_{2}$ & $2.47_{6}$ & $2.57_{2}$ \\
\hline 24.673 & $2.06_{3}$ & $2.12_{7}$ & $2.18_{8}$ & $2.24_{8}$ & $2.31_{0}$ & $2.37_{3}$ & $2.47_{2}$ & $2.56_{4}$ \\
\hline 29.591 & $2.06_{7}$ & $2.13_{3}$ & $2.19_{5}$ & $2.25_{5}$ & $2.31_{6}$ & $2.37_{4}$ & $2.46_{8}$ & $2.55_{6}$ \\
\hline 34.508 & $2.07_{1}$ & $2.14_{0}$ & $2.20_{3}$ & $2.26_{2}$ & $2.32_{1}$ & $2.37_{5}$ & $2.46_{4}$ & $2.54_{8}$ \\
\hline 39.426 & $2.07_{5}$ & $2.14_{6}$ & $2.21_{0}$ & $2.26_{9}$ & $2.32_{7}$ & $2.37_{6}$ & $2.45_{9}$ & $2.54_{0}$ \\
\hline 44.343 & 2.079 & $2.15_{2}$ & $2.21_{7}$ & $2.27_{7}$ & $2.33_{2}$ & $2.37_{7}$ & $2.45_{5}$ & $2.53_{2}$ \\
\hline 49.261 & $2.08_{2}$ & $2.15_{8}$ & $2.22_{5}$ & $2.28_{4}$ & $2.33_{8}$ & $2.37_{8}$ & $2.45_{1}$ & $2.52_{4}$ \\
\hline 54.178 & $2.08_{6}$ & $2.16_{4}$ & $2.23_{2}$ & $2.29_{1}$ & $2.34_{3}$ & $2.37_{9}$ & $2.44_{7}$ & $2.51_{6}$ \\
\hline 59.096 & $2.08_{9}$ & $2.16_{9}$ & $2.23_{8}$ & $2.29_{7}$ & $2.34_{8}$ & $2.38_{0}$ & $2.44_{3}$ & $2.50_{9}$ \\
\hline
\end{tabular}

\section{Acknowledgements}

This work was financially supported by Fundação para a Ciência e Tecnologia, Portugal, under contract POCTI/EQU/34955. R.G.A. and J.M.S.S.E. are grateful to Fundação para a Ciência e Tecnologia for doctoral fellowships.

\section{References}

[1] J.P.M. Trusler, Physical Acoustics and Metrology of Fluids, Adam Hilger, Bristol, 1991.

[2] G. Douhéret, M.I. Davis, J.C.R. Reis, M.J. Blandamer, Chem. Phys. Chem. 2 (2001) 148-161.

[3] P.F. Pires, H.J.R. Guedes, J. Chem. Thermodyn. 31 (1999) 55-69.

[4] S.J. Ball, J.P.M. Trusler, Int. J. Thermophys. 22 (2001) 427-443.

[5] R.C. Asher, Ultrasonic Sensors, Institute of Physics Publishing, Bristol, 1997.

[6] H.J. McSkimin, in: W.P. Mason (Ed.), Physical Acoustics Principles and Methods, vol. 1, Part A, Academic Press, New York, 1964 (Chapter 4).

[7] J.L. Daridon, A. Lagrabette, B. Lagourette, J. Chem. Thermodyn. 30 (1998) 607-623.

[8] J.P. Petitet, R. Tufeu, Int. J. Thermophys. 4 (1983) 35-50.

[9] V. Kozhevnikov, D. Arnold, E. Grodzinskii, S. Naurzakov, Fluid Phase Equilib. 125 (1996) 149-157.

[10] H.F. Eden, E.G. Richardson, Acustica 10 (1960) 309-315.

[11] J. Timmermanns, Physico-Chemical Constants of Binary Systems, Interscience, New York, 1950, p. 355.

[12] H.T. French, J. Chem. Thermodyn. 21 (1989) 801-809.

[13] R. Malhotra, L.A. Woolf, J. Chem. Thermodyn. 23 (1991) 867 876.

[14] H. Pöhler, E. Kiran, J. Chem. Eng. Data 42 (1997) 379-383.
[15] Z.S. Kooner, W.A. Van Hook, J. Phys. Chem. 92 (1988) 6414 6426.

[16] M.J.P. Muringer, N.J. Trappeniers, S.N. Biswas, Phys. Chem. Liq. 14 (1985) 273-296.

[17] R. Vedam, G. Holton, J. Acoust. Soc. Am. 43 (1968) 108-116.

[18] T.F. Sun, C.A.T. Seldam, P.J. Kortbeek, N.J. Trappeniers, S.J. Biswas, Phys. Chem. Liq. 18 (1988) 107-116.

[19] A. Lainez, J.F. Miller, J.A. Zollweg, W.B. Streett, J. Chem. Thermodyn. 19 (1987) 1251-1260.

[20] Landolt-Börnstein, Neue Serie, BdII/5, Springer-Verlag, Heidelberg, 1966, p.19.

[21] D. Papaionnou, D. Ziakas, C. Panayiotou, J. Chem. Eng. Data 36 (1991) 35-39.

[22] I.R. Low, E.A. Moelwyn-Hughes, Proc. R. Soc. London A 267 (1962) 384.

[23] L.A.K. Staveley, W.I. Tupman, K.R. Hart, Trans. Faraday Soc. 51 (1955) 323-343.

[24] R.M. Ibberson, W.I.F. David, O. Yamamuro, T. Matsuo, H Suga, J. Phys. Chem. 99 (1995) 14167-14173.

[25] A. Imre, K. Martinás, L.P.N. Rebelo, J. Non-Equilibrium Thermodyn. 23 (1998) 351-375.

[26] H.I.M. Veiga, L.P.N. Rebelo, M. Nunes da Ponte, J. Szydlowski, Int. J. Thermophys. 22 (2001) 1159-1174.

[27] Z.P. Visak, L.P.N. Rebelo, J. Szydlowski, J. Chem. Educ. 79 (2002) 869-873.

[28] L.P.N. Rebelo, Z.P. Visak, J. Szydlowski, H.I.M. Veiga, R. Gomes de Azevedo, P.F. Pires, M. Nunes da Ponte, in: A.R. Imre, H.J. Maris, P.R. Williams (Eds.), Liquids Under Negative Pressure, NATO Science Series, Kluwer Academic Publishers, Dordrecht, 2002, pp. 95-108.

[29] J.C.G. Calado, H.J.R. Guedes, M. Nunesda Ponte, L.P.N. Rebelo, W.B. Streett, J. Phys. Chem. 90 (1986) 1892-1896.

[30] J.H. Dymond, R. Malhotra, Int. J. Thermophys. 9 (1988) 941951.

JCT 03/092 